Article

\title{
Gold Nanoparticles for Targeting Varlitinib to Human Pancreatic Cancer Cells
}

\author{
Sílvia Castro Coelho *, Daniel Pires Reis (i), Maria Carmo Pereira and Manuel A. N. Coelho \\ LEPABE—Laboratory for Process Engineering, Environment, Biotechnology and Energy, Faculty of Engineering, \\ University of Porto, Rua Dr Roberto Frias, 4200-465 Porto, Portugal; reis.danielp@gmail.com (D.P.R.); \\ mcsp@fe.up.pt (M.C.P.); mcoelho@fe.up.pt (M.A.N.C.) \\ * Correspondence: silvia.coelho@fe.up.pt; Tel.: +351-225-083-656; Fax: +351-225-081-449
}

Received: 3 May 2018; Accepted: 10 July 2018; Published: 12 July 2018

\begin{abstract}
Colloidal gold nanoparticles are targeting probes to improve varlitinib delivery into cancer cells. The nanoconjugates were designed by the bioconjugation of pegylated gold nanoparticles with varlitinib via carbodiimide-mediated cross-linking and characterized by infrared and X-ray photoelectron spectroscopy. The drug release response shows an initial delay and a complete drug release after $72 \mathrm{~h}$ is detected. In vitro experiments with MIA PaCa-2 cells corroborate that PEGAuNPsVarl conjugates increase the varlitinib toxic effect at very low concentrations (IC50 $=80 \mathrm{nM}$ ) if compared with varlitinib alone (IC50 $=259 \mathrm{nM}$ ). Our results acknowledge a decrease of drug side effects in normal cells and an enhancement of drug efficacy against to the pancreatic cancer cells reported.
\end{abstract}

Keywords: gold nanoparticles; tyrosine conjugation; pancreatic cells

\section{Introduction}

Varlitinib is a tyrosine kinase inhibitor of the epidermal growth factor receptor (EGFR) family, controlling cell growth, differentiation, and survival. It selectively and reversibly binds to both EGFR (ErbB-1) and Her-2/neu (ErbB-2) and prevents their phosphorylation and activation [1]. Several reports suggested varlitinib as a selective anticancer-drug and inhibitor of EGFR/ErbB-2 [1-3]. The tyrosine kinase inhibitor can reverse, significantly, the multidrug resistance (MDR) in cancer cells resulting from the inhibition of the ATP-binding cassette $(\mathrm{ABC})$ transporters that act in extruding a variety of chemotherapeutic agents out of the tumour cells [2]. Some studies reported an efficient in vitro activity of varlitinib in combination with other anticancer drugs in several tumour models, suggesting varlitinib not only as a potent single tyrosine kinase inhibitor but also with high tolerability with other drugs $[2,4]$.

The primary problem in the cancer treatments with chemotherapeutic agents has been the high toxicity and low bioavailability of the anticancer therapy. The tumour heterogeneity and the MDR are the key challenge in anticancer therapy [5]. Trying to avoid such problems, nanoparticles (NPs) have been a challenge for delivering of the anticancer drugs to the tumour cells [6]. They have been promising tools to attain better retention and release of therapeutic and diagnosis agents, and furthermore, to overcome the conventional therapeutic limitations [7-9]. A good effort of this application are inorganic nanosized vehicles such as gold nanoparticles (AuNPs) [10]. Due to their distinct optical and chemical properties-easy preparation, characteristic surface plasmon resonance (SPR) band, simple chemistry, and high functionalizable surface - they have been studied as drug delivery vehicles and imaging agents [11-13]. They present a significant biocompatibility and their production costs are very low, which facilitated their use [14,15]. AuNPs can be synthesized via different methods, with different shape (spheres, rods, tubes, wires, ribbons, cubic, hexagonal, triangular) and size [16-18]. AuNPs present small sizes that can allow the enhanced permeation and retention (EPR) effect and minimize 
reticuloendothelial system (RES) clearance $[19,20]$. There are successful in vitro studies reporting a better inhibition of tumour cell proliferation using conjugated gold nanoparticles with anticancer drugs compared with the same free drugs [21-25]. Aryal et al. reported the conjugation of AuNPs with doxorubicin using thiolated methoxy polyethylene glycol as a linker [13]. Coelho et al. studied pegylated AuNPs with afatinib, which present a potential drug delivery nanosystem to enhance the toxicity of the drug against pancreatic as well as non-small lung cancer cell lines [25]. To improve the stability of the colloidal suspension and to inhibit protein adsorption to their surface, the nanoparticles can be modified covalently [15]. $\alpha$-thiol-carboxyl (polyethylene glycol) can be bound to the surface of gold nanoparticles [15]. This uncharged polymer is non-toxic and minimizes the electrostatic interactions with plasma proteins [26,27]. The coupling reaction of the activator $N$-ethyl- $N^{\prime}$-(3-dimetylaminopropyl) carbodiimide (EDC) and sulfo- $\mathrm{N}$-hydroxysuccinimide (NHSS) is used to mediate the formation of linkage between carboxylic and amino-terminated groups [28].

In the present study, the aim was to obtain conjugated gold nanoparticles to evaluate its effect into human pancreatic cells: MIA PaCa-2, a pancreatic cancer cell line that express high levels of HER2/neu and EGFR [21,29,30], and hTERT-HPNE, an immortalized human pancreatic duct epithelial cells [31]. Conjugates of gold nanoparticles to varlitinib have not yet been reported.

Pegylated gold nanoparticles were synthesized and conjugated with varlitinib via carbodiimidemediated cross-linking. The nanoconjugate was characterized by using ultraviolet visible (UV-Vis), dynamic light scattering (DLS) and laser Doppler velocimetry, Attenuated Total Reflectance-Fourier Transform Infrared Spectroscopy (ATR-FTIR), X-ray photoelectron spectroscopy (XPS), transmission electron microscopy (TEM) techniques, in vitro drug release, and in vitro drug stability analysis. Our results showed that pegylated gold nanoparticles represent a promising drug delivery nanosystem, enhancing the varlitinib cell toxicity in pancreatic cancer cell lines.

\section{Materials and Methods}

\subsection{Materials}

Varlitinib was acquired from Selleck Chemicals LLC (Houston, TX, USA). Phosphate buffered saline (PBS) and fetal bovine serum (FBS) was purchased from Invitrogen Co. (Scotland, UK). Dimethyl sulfoxide (DMSO), trisodium citrate dihydrate and tetrachloroauric (III) acid- $\mathrm{HAuCl}_{4} ; 99.99 \%$ trace metals basis, $30 \mathrm{wt} \%$ in dilute $\mathrm{HCl}$-were acquired from Sigma-Aldrich Química (Sintra, Portugal). a-thiol-w-carboxyl (polyethylene glycol) (HS-C11-(EG)3-OCH2-COOH; molecular weight 394.57 Da) was obtained from Prochimia (Gdynia, Poland).

\subsection{Cell Culture}

Immortalized human pancreatic duct epithelial cells (hTERT-HPNE) were provided by Professor M. A. Hollingsworth (UNNC-Omaha, NE, USA). Human pancreatic carcinoma cells (MIA PaCa-2) were obtained from the LGC Standards (Barcelona, Spain). The cells were maintained in DMEM medium, supplemented with $10 \% \mathrm{FBS}$ under $5 \% \mathrm{CO}_{2}$ humidified atmosphere at $37^{\circ} \mathrm{C}$.

\subsection{Synthesis of Pegylated Gold Nanoparticles}

Gold nanoparticles (AuNPs) were prepared by the reduction process of $\mathrm{HAuCl}_{4}$ through a solution of trisodium citrate [17,32]. Then, AuNPs were functionalized with a-thiol-w-carboxyl (polyethylene glycol) layer (molar ratio 1:1000, respectively)-PEG. PEGAuNPs were collected by centrifugation (13,400 g, $10 \mathrm{~min}$ ) and resuspended in ultrapure water. The concentration of the PEGAuNPs, determined by the Lambert-Beer Law was $15.08 \mathrm{nM}$. 


\subsection{Conjugation of Varlitinib to PEGAuNP, PEGAUNPsVarl}

Varlitinib was conjugated to PEGAuNPs using the EDC/NHSS coupling (molar ratio 1000:1, respectively) for $2.5 \mathrm{~h}$. The PEGAuNPVarl was centrifuged $(13,000 \times g)$ to remove the unbound varlitinib drug.

\subsection{Dynamic Light Scattering and Electrophoretic Mobility Measurements}

Size distribution and zeta potential of nanoconjugates were determined by dynamic light scattering and laser doppler velocimetry, respectively, using a Zetasizer Nano ZS (Malvern Instruments Ltd., Malvern, $\mathrm{UK})$, at $25^{\circ} \mathrm{C}$.

\subsection{Ultraviolet Visible Spectroscopy}

PEGAuNPs and PEGAuNPsVarl were analysed by UV-Vis spectroscopy (Shimadzu UV-1700 PharmaSpec spectrophotometer, Kyoto, Japan), using a $1 \mathrm{~cm}$ quartz cuvette, at room temperature.

\subsection{Attenuated Total Reflectance-Fourier Transform Infrared Spectroscopy (ATR-FTIR)}

The suspensions of PEGAuNPsVarl and PEGAuNPs, and varlitinib solutions were analysed by ATR-FTIR spectroscopy (ALPHA FTIR Spectrometer, Bruker, Billerica, MA, USA). Spectral scanning was acquired in the $4000-400 \mathrm{~cm}^{-1}$, resolution of $4 \mathrm{~cm}^{-1}$, and 64 scans, at $25^{\circ} \mathrm{C}$.

\subsection{Transmission Electron Microscopy (TEM) Analysis}

TEM images were acquired using a Jeol JEM-1400 (Peabody, MA, USA), JEOL operated at 60 kV. An amount of $5 \mu \mathrm{L}$ of each sample was placed on carbon formvar-coated grid and let to adsorb for 5 min. After, the grid was washed twice with deionized (DI) water to remove the excess.

\subsection{X-Ray Photoelectron Spectroscopy (XPS) Analysis}

XPS was performed on a Kratods Axis Ultra HAS instrument (Manchester, UK) using a monochromator Al X-ray anode source operated at 90 W. Samples-AuNPs, PEGAuNPs, and PEGAuNPsVarl—were prepared by drop on a clean microscope slide and the drops were allowed to air dry before the analysis.

\subsection{Varlitinib/PEGAuNPs Conjugation Efficiency}

The PEGAuNPsVarl formulations were centrifuged $(13,000 \times g, 15 \mathrm{~min})$ and the supernatant was collected to measure varlitinib concentration by fluorescence measures (excitation at $360 \mathrm{~nm}$, emission at $485 \mathrm{~nm}$ ). The conjugation efficiency was evaluated by:

(Varlitinib initial concentration - Varlitinib supernatant concentration)/Varlitinib initial concentration

The results are presented as mean and SD of at least three independent experiments.

\subsection{In Vitro Drug Release Studies}

The in vitro release profile of PEGAuNPsVarl was performed by dialysis. Nanoconjugates with $4.2 \mu \mathrm{M}$ of varlitinib concentration were incubated in PBS $0.01 \mathrm{M}, \mathrm{pH} 7.4$, at $37^{\circ} \mathrm{C}$ with constant magnetic stirring in regenerated cellulose. Varlitinib concentration of the dialysate buffer was determined with time through fluorescence measures using a microplate reader (PowerWave HT Microplate Spectrophotometer, BioTek Instruments Inc., Winooski, VT, USA) (excitation at $360 \mathrm{~nm}$, emission at $485 \mathrm{~nm}$ ). Varlitinib concentration of the dialysate buffer was determined with time through fluorescence measures using a microplate reader (PowerWave HT Microplate Spectrophotometer, BioTek, Instruments Inc., Winooski, VT, USA) (excitation at $360 \mathrm{~nm}$, emission at $485 \mathrm{~nm}$ ). 


\subsection{In Vitro Stability Studies}

PEGAuNPs $8 \mathrm{nM}$ and PEGAuNPsVarl $5 \mathrm{nM}$ were incubated in PBS $0.01 \mathrm{M}$, at $4{ }^{\circ} \mathrm{C}$ and in FBS $10 \%(v / v)$ in PBS solution, at $37^{\circ} \mathrm{C}$. Samples were evaluated at several time points post incubation during $72 \mathrm{~h}$ by using DLS, UV-Vis spectroscopy and laser Doppler velocimetry.

\subsection{In Vitro Cytotoxicity Study}

In vitro cytotoxicity of varlitinib and PEGAuNPsVarl against pancreatic cell lines was evaluated by SRB (colorimetric) [33]. Briefly, the MIA PaCa-2 and hTERT- HPNE cells were seeded on 96-well plates with a cell density at 1000 cells per well, under normal conditions $\left(5 \% \mathrm{CO}_{2}\right.$ humidified atmosphere at $37^{\circ} \mathrm{C}$ ) and allowed to adhere for $24 \mathrm{~h}$. Then, the cells were treated for $48 \mathrm{~h}$ with varlitinib and PEGAuNPsVarl at the concentrations ranging between 10 and $1000 \mathrm{nM}$ varlitinib. Cells were fixed with $10 \%(w / v)$ TCA for 60 min on ice. Next, the cells were washed with water and stained with $50 \mu \mathrm{L}$ of SRB solution. The unbound dye was removed by washing with $1 \%(v / v)$ acetic acid. The dried cells and the protein-bound stain were solubilized with $10 \mathrm{mM}$ Tris solution. The SRB absorbance was measured at $560 \mathrm{~nm}$ in a microplate reader (Synergy HT Multi-Mode Microplate Reader, BioTek Instruments Inc., Winooski, VT, USA). The IC50 (concentration for 50\% of cell survival) and GI50 (50\% of growth inhibition) values were determined. The absorbance of the wells containing the NPs or drug and the absorbance of the wells containing untreated cells following a 48 -h incubation period were subsequently compared with that of the wells containing the cells that have been fixed at time zero (corresponding to incubation of the nanoparticles and drug).

\subsection{Statistical Analysis}

Values are reported as mean of three independent experiments. Student's $t$-test statistical analysis was used to determine statistical significance $((p<0.05)$.

\section{Results and Discussion}

Spherical AuNPs were firstly synthesized by the classical Turkevitch method and presented in TEM image (Figure 1a) $[32,33]$. The nanoparticles were prepared by reduction of the $\mathrm{HAuCl}_{4}$ solution with sodium citrate. They present a hydrodynamic diameter of $20.0 \pm 0.2 \mathrm{~nm}$ (Table 1), results obtained by DLS analysis.
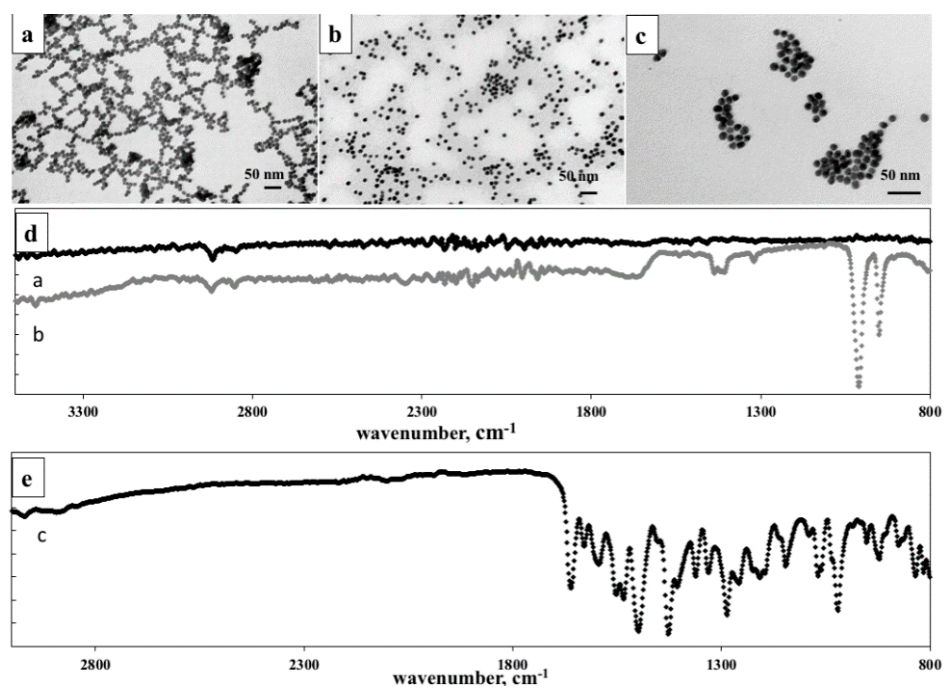

Figure 1. TEM images of (a) AuNPs, (b) PEGAuNPs, (c) PEGAuNPsVarl. Scale bar is $50 \mathrm{~nm}$; (d) FTIR spectra of PEGAuNPsVarl (black line) and PEGAuNPs (grey line), (e) FTIR spectra of varlitinib (black dots). The spectra were shifted for a better visualization. 
The final concentration of stock AuNPs was $14 \pm 1 \mathrm{nM}$, determined by Lambert-Beer law and absorbance peak at $520 \mathrm{~nm}$ characteristic by the reduction of $\mathrm{HAuCl}_{4}$ to AuNPs [34].

The morphology of different AuNPs samples was characterized by TEM. After functionalization of the AuNPs surface with PEG layer via Au-S bonds, PEGAuNPs did not change in shape and the size is increased slightly (Figure 1b). This result agrees with the size distribution (PdI 0.3) indicating a good monodisperse distribution of the colloidal suspension which nanoparticles have an average hydrodynamic diameter of $27 \pm 2 \mathrm{~nm}$ and a zeta potential $-34 \pm 1 \mathrm{mV}$ confirming their stability (Table 1). The nanoparticles were stable for several months when stored at $4{ }^{\circ} \mathrm{C}$ in aqueous dispersion. The concentration of PEGAuNPs $8.9 \pm 0.8 \mathrm{nM}$ was estimated from UV-Vis spectra. As shown in Figure S1 UV-Vis spectra showed the presence of a surface plasmon resonance band centered at $522 \mathrm{~nm}$, determined by UV-Vis absorption spectroscopy.

Table 1. Physical characteristics of AuNPs, PEGAuNPs, and PEGAuNPsVarl.

\begin{tabular}{cccc}
\hline Physical Characteristics & AuNPs & PEGAuNPs & PEGAuNPsVarl \\
\hline size, $\mathrm{nm}$ & $20.0 \pm 0.2$ & $27 \pm 2$ & $28 \pm 2$ \\
polydispersity index & 0.2 & 0.3 & 0.7 \\
zeta potential, $\mathrm{mV}$ & $-37 \pm 3$ & $-34 \pm 1$ & $-33 \pm 1$
\end{tabular}

AuNPs: gold nanoparticles; PEGAuNPs: Pegylated gold nanoparticles; PEGAuNPsVarl: Pegylated gold nanoparticles conjugated with varlitinib.

The resultant nanoparticles-PEGAuNPs—-were conjugated with varlitinib (PEGAuNPsVarl) by using the EDC/NHSS crosslinking of carboxylic acids from PEGAuNPs with secondary amine group of varlitinib (Figure 2a), illustrated in Figure $2 b$.

a

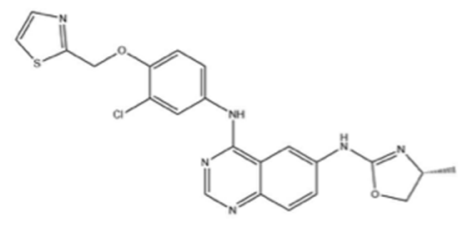

b
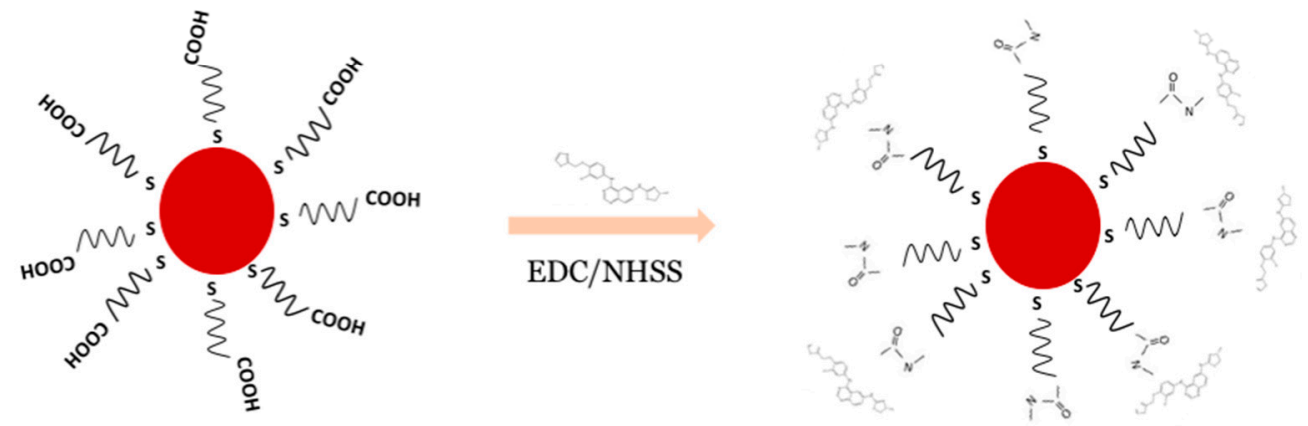

Figure 2. (a) Chemical structure of varlitinib; (b) Scheme of nanoconjugate PEGAuNPsVarl preparation.

Table 1 shows the average hydrodynamic diameter measurements of PEGAuNPsVarl. They have $28 \pm 2 \mathrm{~nm}$ and the zeta potential is $-33 \pm 1 \mathrm{mV}$. Also, TEM image (Figure 1c) illustrated well-defined nanoconjugates with small diameters as DLS measurements and the formation of some aggregated nanoparticles. The surface plasmon resonance peak of the designed nanoconjugates showed a red shift of $2 \mathrm{~nm}$ compared to that of original PEGAuNPs (wavelength of $522 \mathrm{~nm}$ ) and their estimated concentration was $3.5 \pm 0.8 \mathrm{nM}$.

The varlitinib conjugation efficiency was determined through fluorescence analysis. Per the data, $84 \pm 1 \%(w / w)$ of varlitinib was conjugated with PEGAuNPs (by subtracting the unbound varlitinib in 
the supernatant solution). Therefore, the final varlitinib concentration in stock PEGAuNPs solution was determined to be $4.4 \pm 0.5 \mu \mathrm{M}$.

Figure $1 \mathrm{~d}$ indicated the FTIR analysis of nanoparticles to understand and confirm the covalent bonds. In Figure 1d, the ATR-FTIR spectrum of unmodified PEGAuNPs showed characteristic peaks at $1741 \mathrm{~cm}^{-1}$ from carbonyl $\mathrm{C}=\mathrm{O}$ stretching and at $1317 \mathrm{~cm}^{-1}$ from $\mathrm{C}-\mathrm{OH}$ stretching group of the ethylene glycol monomers. At 1151 and $1165 \mathrm{~cm}^{-1}$, the peaks to the $\mathrm{C}-\mathrm{O}-\mathrm{C}$ groups were observed, and at $2917 \mathrm{~cm}^{-1}$ it appeared the vibrational stretches of $-\mathrm{CH}_{2}$ groups of long alkane chains from PEG. In the FTIR spectrum of PEGAuNPsVarl, the peak at $1671 \mathrm{~cm}^{-1}$ indicates the $\mathrm{C}=\mathrm{N}$ that can be assigned to the imine vibration from reaction of secondary amine of varlitinib with carboxylic acid of PEGAuNPs (Figure 1d) [28]. The peaks at 1407, 1418, and $1437 \mathrm{~cm}^{-1}$ represent the $C=C$ stretch from aromatic groups of varlitinib (Figure 1e). At $807 \mathrm{~cm}^{-1}$, the peaks are visible of $\mathrm{C}-\mathrm{H}$ aromatic out-of-plane bending. At 950 and $1011 \mathrm{~cm}^{-1}$, varlitinib peaks appeared $-\mathrm{C}-\mathrm{H}$ aromatics out-of-plane bend and $\mathrm{C}-\mathrm{N}$ amine group, respectively.

Moreover, AuNPs, PEGAuNPs, and PEGAuNPsVarl were further analysed by XPS as shown in Figure S2. The contributions of elements, $\mathrm{Au}, \mathrm{C}, \mathrm{N}, \mathrm{O}$ atoms are displayed in Figure 3. The binding energy of $\mathrm{Au} 4 \mathrm{f}$ of samples exhibits at 83.6 and $87.25 \mathrm{eV}$, which is higher than that of PEGAuNPs at 83.54 and $87.18 \mathrm{eV}$. Also, these data show the presence of three carbon peaks at 284.9, 286.7, and 288.9 indicating $\mathrm{sp}^{3}$ - (in saturated hydrocarbons) and $\mathrm{sp}^{2}$ - hybridized carbons (such as $\mathrm{C}=\mathrm{C}$ and $\mathrm{C}=\mathrm{O}$ ). It corroborates with a covalent interaction between AuNPs and PEG-COOH. The signal of $\mathrm{N}$ at $399.76 \mathrm{eV}$ is observed for PEGAuNPsVarl (Figure S2c) and the signal of O decreased, suggesting a covalent bonding of the varlitinib nitrogen to PEGAuNPs, in accordance with FTIR data.
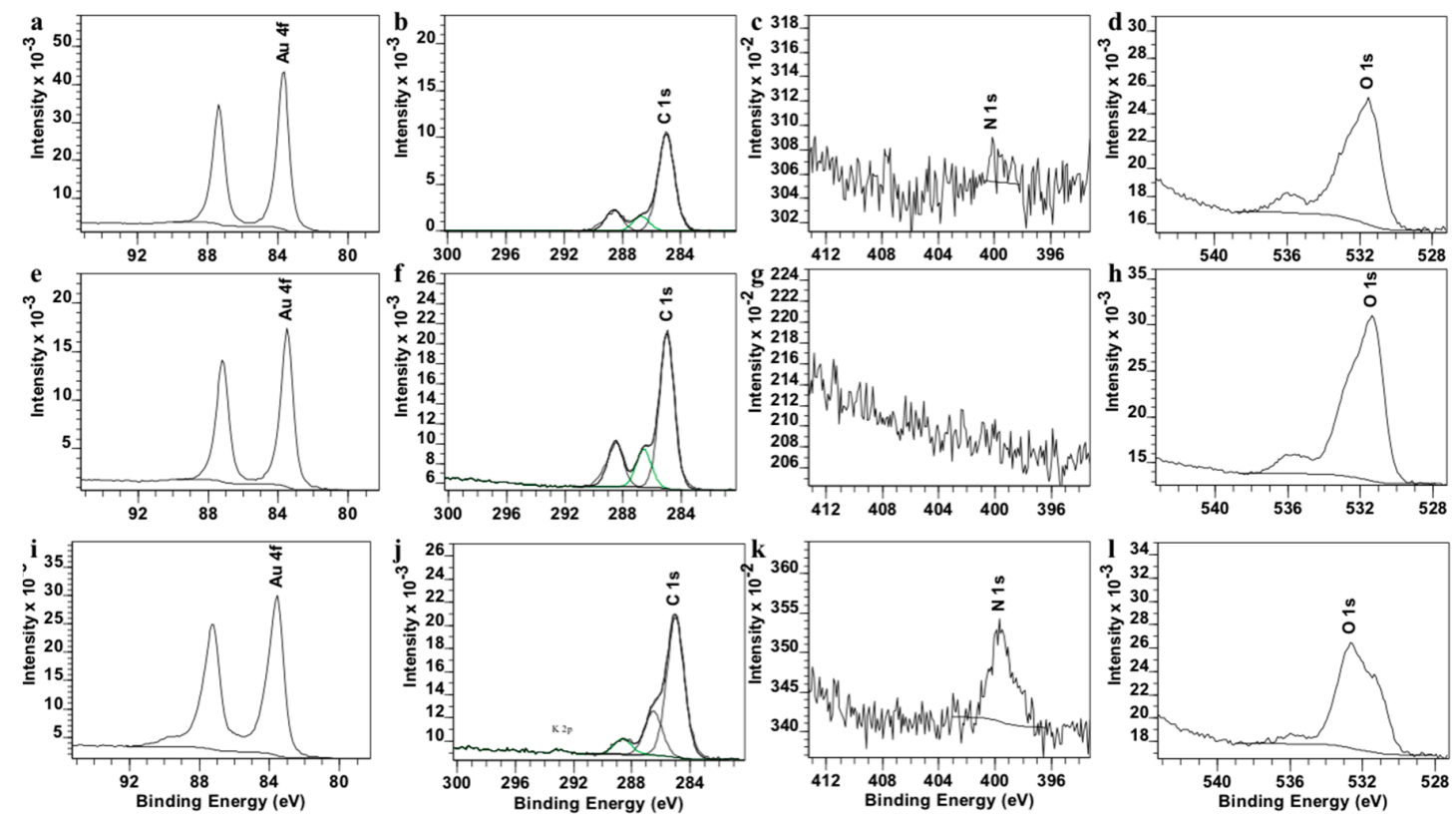

Figure 3. XPS deconvolution of Au $4 \mathrm{f}(\mathbf{a}, \mathbf{e}, \mathbf{i}), \mathrm{C} 1 \mathrm{~s}(\mathbf{b}, \mathbf{f}, \mathbf{j}), \mathrm{N}(\mathbf{c}, \mathbf{g}, \mathbf{k})$, and $\mathrm{O}(\mathbf{d}, \mathbf{h}, \mathbf{l})$ of AuNPs (a-d), PEGAuNPs (e-h), and PEGAuNPsVarl (i-1).

Table 2 showed the XPS elemental composition on the regions of interest. According to the XPS composition data, the signal of $C$ increased from $60.4 \%$ (AuNPs) of the sample to $65.1 \%$ (PEGAuNPs and PEGAuNPsVarl), representing the good functionalization with PEG layer. Also, the signal of $\mathrm{N}$ on PEGAuNPsVarl is distinct $(1.60 \%)$, indicating the presence of varlitinib. 
Table 2. XPS elemental composition of AuNPs, PEGAuNPS, and PEGAuNPsVarl (at \% normalized to 100\%).

\begin{tabular}{cccc}
\hline Element & AuNPs & PEGAuNPs & PEGAuNPsVarl \\
\hline C 1s & 60.44 & 65.05 & 65.06 \\
N 1s & 0.06 & - & 1.60 \\
Au 4f & 16.77 & 4.82 & 13.80 \\
O 1s & 22.73 & 30.14 & 19.55 \\
\hline
\end{tabular}

The time-dependent absorbance spectra, hydrodynamic diameter, and zeta potential were performed to investigate the stability of PEGAuNPsVarl and PEGAuNPs in PBS at $4{ }^{\circ} \mathrm{C}$ for $72 \mathrm{~h}$, and were presented in Figures S3a-S5a. PEGAuNPs were stable over $72 \mathrm{~h}$ of incubation in PBS at $4{ }^{\circ} \mathrm{C}$. They had $29.8 \mathrm{~nm}$ and a zeta potential of $-24.0 \pm 0.7 \mathrm{mV}$ (Figures S3a and S4a). The behaviour of PEGAuNPsVarl in PBS at $37^{\circ} \mathrm{C}$ did not change significantly. In fact, the particles changed its hydrodynamic diameter to $31.3 \mathrm{~nm}$ (Figure S3a), data in accordance with the increase of the wavelength value of the plasmon peak (Figure S5a). Also, on Figure S4a, it was observed that NPs had $-24.1 \pm 0.5 \mathrm{mV}$ of zeta potential which remained unchanged for $48 \mathrm{~h}$; after this period, it tends to be less negative $(-22.4 \pm 0.4 \mathrm{mV})$.

The PEGAuNPsVarl stability in the presence of fetal bovine serum (FBS) was evaluated by hydrodynamic diameter, zeta potential measurements and time-dependent absorbance spectra, at $37^{\circ} \mathrm{C}$ for $72 \mathrm{~h}$ (Figures S3b-S5b). In the presence of FBS, two populations are present: a core population with $33 \pm 2 \mathrm{~nm}(86 \%)$ and a minor population with $134 \pm 4 \mathrm{~nm}(14 \%)$, due to the FBS protein absorption into the nanoconjugates (Figure S3b). A slight increase was observed at $72 \mathrm{~h}$. The PEGAuNPs zeta potential values decreased to $-9 \pm 1 \mathrm{mV}$, which are justified by the adsorption of proteins and ions to the nanoconjugates reducing the electrostatic repulsion between them favouring some aggregation.

The in vitro drug controlled release experimental of PEGAuNPsVarl was performed in PBS $\left(0.01 \mathrm{M}, \mathrm{pH} 7.4\right.$ at $\left.37^{\circ} \mathrm{C}\right)$ through a regenerated cellulose dialysis membrane with an initial varlitinib concentration in NPs of $4.2 \mu \mathrm{M}$. Figure 4 presented the drug release data. It is possible to visualize an initial delay of $4 \mathrm{~h}$. After $8 \mathrm{~h}$, around $20 \%$ of the varlitinib amount was released. Figure 4 indicates a slow and controlled release of the drug conjugated with the nanoparticles that might be explained from conjugated NPs. The conjugated PEGAuNPs release about $93 \pm 6 \%$ of the varlitinib for $72 \mathrm{~h}$, suggesting the disruption of the covalent bond of thiol-PEG with gold nanoparticles due to the temperature increase [35].

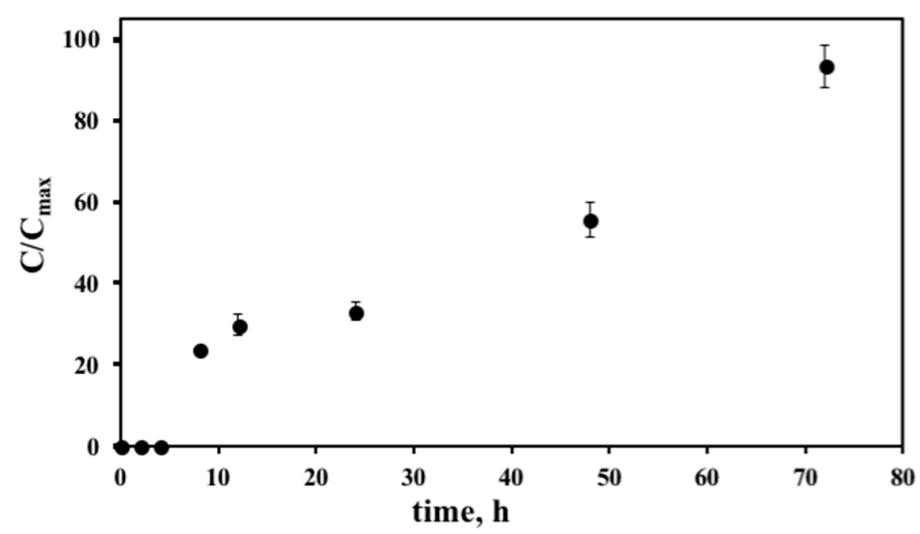

Figure 4. The varlitinib release profile of the PEGAuNPsVarl in PBS at $\mathrm{pH} 7.4$ and $37^{\circ} \mathrm{C}$.

$C_{\max }$ corresponds to the total amount of the drug added. Results are shown as mean \pm SEM of three independent experiments.

The in vitro cytotoxic effects after treatment with varlitinib alone and PEGAuNPsVarl were assessed on MIA PaCa-2 and hTERT-HPNE cell. Treatment with PEGAuNPs at concentrations up to $2 \mathrm{nM}$, during $48 \mathrm{~h}$ of incubation, did not presented effect on the cell growth (data not shown) 
corroborating non-toxicity of the PEGAuNPs [33]. The effect of varlitinib at different concentrations (10 to $1000 \mathrm{nM}$ ) was tested and cell growth analysed. Figure 5 shows the cell survival results of the cell lines after incubation with PEGAuNPsVarl and varlitinib alone for $48 \mathrm{~h}$, and PEGAuNPsVarl toxicity was compared with varlitinib alone. The cell survival of MIA PaCa-2 cells decreases after exposure with both free and conjugated varlitinib (Figure 5a,c). On MIA PaCa-2, for varlitinib concentration of $100 \mathrm{~nm}$, toxicity of varlitinib conjugated PEGAuNPs was higher than varlitinib alone (44\% of the cell survival for VarlPEGAuNPs and $80 \%$ for varlitinib alone). These results can be explained by cancer cell environment specifically acidic $\mathrm{pH}$ gradient and hypoxia promoting nanoparticle uptake via endocytosis and, as a result, drug concentration increases in the cytoplasm [33,36-38]. Also, MIA PaCa-2 cells overexpress high levels of HER2/neu and EGFR [21,29,30] that can be inhibited and reversibly bounded to varlitinib [1].

The same trend is observed when analyzing inhibition of cell growth in response to varlitinib alone and conjugated to PEGAuNPs. For MIA PaCa-2s, the nanoconjugate improves the varlitinib activity resulting lower GI50 values (Table 3 and Figure 5e). In $48 \mathrm{~h}$ of incubation, varlitinib alone inhibits the MIA PaCa-2 cell growth by $50 \%$ with $259.1 \pm 0.4 \mathrm{nM}$ of concentration which is higher when compared with $80 \pm 4 \mathrm{nM}$ of varlitinib concentration conjugated with PEGAuNPs. The efficacy of the PEGAuNPsVarl to induce cell death is more pronounced than that of varlitinib alone for varlitinib concentrations above $250 \mathrm{nM}$ (Figure 5).
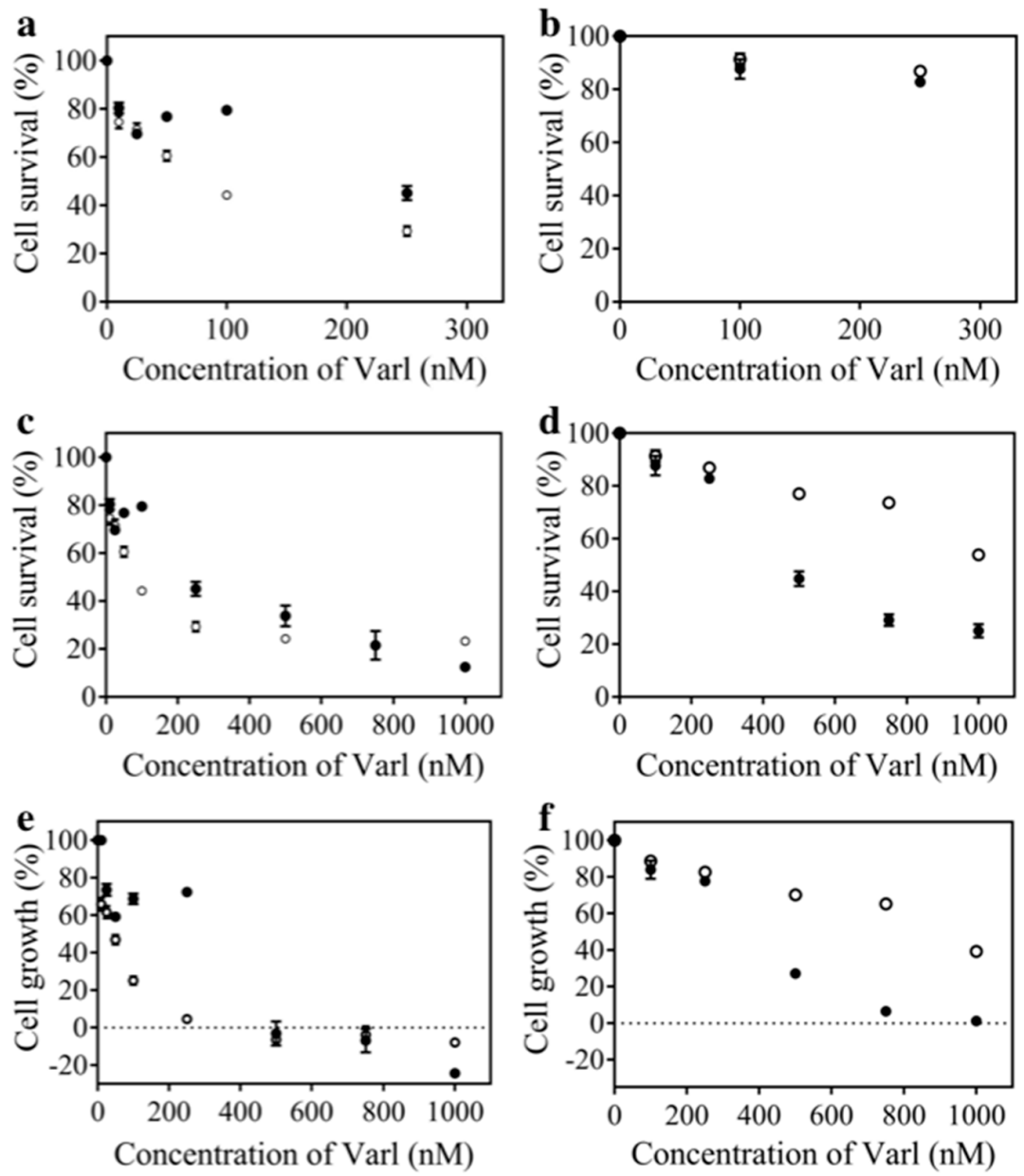

Figure 5. Cytotoxic effects of PEGAuNPsVarl $(\bigcirc)$ and varlitinib alone $(\bullet)$ after $48 \mathrm{~h}$ a treatment on the cell survival (varlitinib concentration range from 10 to $300 \mathrm{nM})(\mathbf{a}, \mathbf{b})$; cell survival (varlitinib concentration range from 10 to $1000 \mathrm{nM})(\mathbf{c}, \mathbf{d})$ and on cell growth $(\mathbf{e}, \mathbf{f})$ of MIA PaCa-2 (a,c,e) and hTERT-HPNE (b,d,f), determined by a SRB assay. 
For the hTERT-HPNE cells, the same effect is not observed (Figure $5 b, d$ ). Our data show that PEGAuNPsVarl inhibited about $23 \%$ of cell survival for varlitinib concentration of $500 \mathrm{nM}$. For the same concentration, varlitinib alone inhibited more than two times (cell survival is around 55\%). hTERT-HPNE displayed higher sensitivity and they presented a significant higher inhibition to varlitinib alone than in presence of the nanoconjugate. In addition, the varlitinib concentrations of PEGAuNPsVarl and varlitinib alone inhibiting cell survival in 50\% (IC50 values) are $1186 \pm 4 \mu \mathrm{M}$ and $478 \pm 5 \mu \mathrm{M}$, respectively (Table 3). This effect might be due to the protection of varlitinib by PEGAuNPs. The nanoparticle behaviour in hTERT-HPNE cells could be related with $\mathrm{pH}$ gradient. Ding et al. reported that in normal cells, the neutral $\mathrm{pH}$ gradient does not promote the nanoparticle internalization when compared with the cancer cell acidic conditions [39]. It was observed a small number of nanoparticles in hTERT-HPNE cytoplasm (Figure 6) in contrast with the nanoparticle concentration detected in pancreatic cancer cells (S2-013) with a clear PEGAuNP accumulation near the nucleus [7,33]. In cancer cells, we have realized a stochastic dynamic formation of endosomes with several gold nanoparticles with a high electron density. This particularity was not observed in hTERT-HPNE cells. The hTERT-HPNE cell morphology does not change significantly with the incubation of the PEGAuNPs alone and conjugated with drug due to the low nanoparticle internalization by the cells, as observed in both tests (Figure $6 \mathrm{~b}, \mathrm{c}$ ). The new findings of PEGAuNPsVarl effect on MIA PaCa-2 and hTERT-HPNE cells corroborate the mechanisms proposed and reported by Coelho et al. [33]
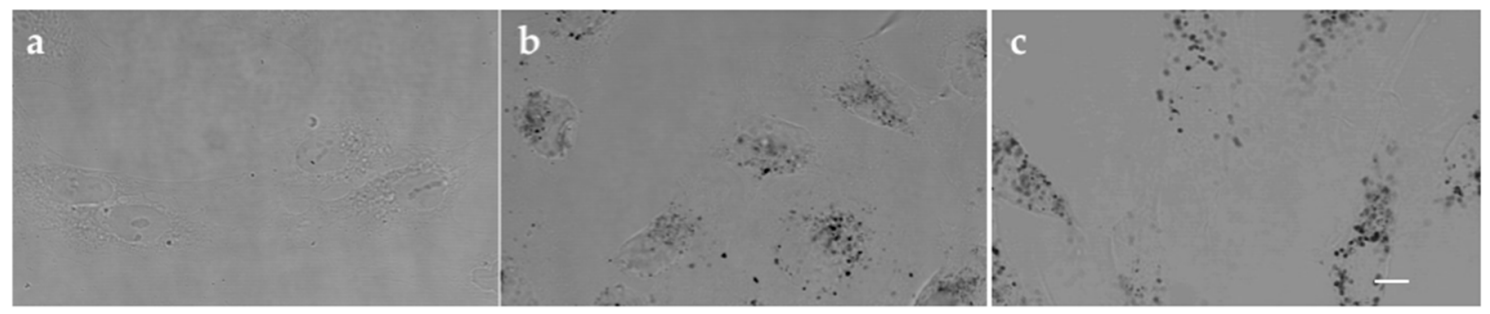

Figure 6. Confocal reflectance images of the hTERT-HPNE cells after $48 \mathrm{~h}$ incubation: (a) control untreated cells; (b) $0.5 \mathrm{nM}$ of PEGAuNPs; (c) $0.5 \mathrm{nM}$ of PEGAuNPsVarl. Scale bar in all images is $10 \mu \mathrm{M}$.

Table 3. Half maximal inhibitory concentration (IC50) and effect of varlitinib alone and PEGAuNPsVarl on the growth inhibition (GI50) on the pancreatic cell lines-MIA PaCa-2 and hTERT-HPNE.

\begin{tabular}{ccccc}
\hline \multirow{2}{*}{ Parametric Analysis } & \multicolumn{2}{c}{ MIA PaCa-2 } & \multicolumn{2}{c}{ hTERT-HPNE } \\
\cline { 2 - 5 } & PEGAuNPsVarl & varlitinib & PEGAuNPsVarl & varlitinib \\
\hline IC50 $(\mathrm{nM})$ & $80 \pm 4$ & $259.1 \pm 0.4$ & $1186 \pm 4$ & $478 \pm 5$ \\
G550 $(\mathrm{nM})$ & $40 \pm 1$ & $268 \pm 7$ & $916 \pm 3$ & $354 \pm 5$ \\
\hline
\end{tabular}

An evan of inhibition hTERT-HPNE cell growth in response to PEGAuNPsVarl and varlitinib alone is observed on Figure 5f). For hTERT-HPNE, the GI50 concentration required to inhibit is 2.5 times lower to varlitinib conjugated with PEGAuNPs than varlit alone $(916 \pm 3 \mathrm{nM}$ and $354 \pm 5 \mathrm{nM}$, respectively). By other hand, the analysis of the balance between cell proliferation and cell death of hTERT-HPNE only showed a decrease of the inhibitory growth with time revealing cell inhibition for both treatments.

\section{Conclusions}

In summary, a well-defined varlitinib delivery system PEGAuNPsVarl was successfully designed and prepared through the EDC/NHSS coupling reaction with a conjugation efficiency of $84 \%$. The in vitro release profiles show a delay on varlitinib release due to the coupling process. The PEGAuNPsVarl shows a significant cancer cell survival inhibition for MIA PaCa-2 cells. In fact, cell survival appeared to decrease by $22-80 \%$ after PEGAuNPsVarl treatment with varlitinib concentration in range from 10 to $1000 \mathrm{nM}$, 
if compared to varlitinib alone. In contrast, cell inhibition in hTERT-HPNE cells by PEGAuNPsVarl is lower, denoting a drop of the nanoconjugate toxic effects in non tumour cells. The varlitinib therapeutic effect is enhanced by the controlled release of the anticancer drug after conjugation with functionalized gold nanoparticles. Our findings indicate that PEGAuNPs can be used as an effective vehicle for varlitinib inhibitor.

The drug delivery system shows potential antineoplastic activity for the treatment of EGFR overexpressed family, decreasing drug doses and the multi-drug resistance effects.

Supplementary Materials: The following are available online at http:/ /www.mdpi.com/1999-4923/10/3/91/s1, Figure S1. UV-Vis spectra of AuNPs, PEGAuNPs and PEGAuNPsVarl. Figure S2. XPS survey spectra of AuNPs (a), PEGAuNPs (b) and PEGAuNPsVarl (c). Figure S3. Size distribution analysis of PEGAuNPs (black column) and PEGAuNPsVarl (striped column) in (a) PBS $0.01 \mathrm{M}$ at $4{ }^{\circ} \mathrm{C}$; (b) FBS at $37^{\circ} \mathrm{C}$, after incubation for different periods of time. Figure S4. Stability analysis of zeta potential property of PEGAuNPs $(\boldsymbol{\Delta})$ and PEGAuNPsVarl $(\bullet)$ in (a) PBS $0.01 \mathrm{M}$ at $4{ }^{\circ} \mathrm{C}$; (b) FBS at $37^{\circ} \mathrm{C}$, after incubation for different periods of time. Figure S5. UV-Vis spectra

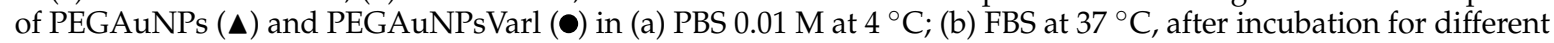
periods of time.

Author Contributions: Conceptualization, S.C.C., M.C.P., and M.A.N.C.; Methodology, D.P.R. and S.C.C.; Software, D.P.R.; Validation, D.P.R. and S.C.C.; Formal Analysis, S.C.C. and D.P.R.; Investigation, S.C.C., D.P.R., M.C.P., and M.A.N.C.; Data Curation, S.C.C.; Writing-Original Draft Preparation, S.C.C.; Writing-Review \& Editing, S.C.C., M.C.P., and M.A.N.C.; Supervision, S.C.C., M.C.P., and M.A.N.C.; Project Administration, M.A.N.C.; Funding Acquisition, M.A.N.C.

Funding: This work was financially supported by: Project POCI-01-0145-FEDER-006939 (Laboratory for Process Engineering, Environment, Biotechnology and Energy-UID/EQU/00511/2013), funded by European Regional Development Fund (ERDF) through COMPETE2020-Programa Operacional Competitividade e Internacionalização (POCI), national funds through FCT-Fundação para a Ciência e a Tecnologia, TRANSCAN-FCT (research project TRANSCAN/0001/2012) and Portuguese Cancer League.

Acknowledgments: We would like to thank Rui Fernandes for the collaboration with TEM analysis, and Carlos Sá and Daniela Silva (CEMUP) for the collaboration with XPS work and analysis. We wish to thank Michael A. Hollingsworth, $\mathrm{PhD}$ and the UNMC Pancreatic SPORE (2 P50 CA127297) for providing cell lines (hTERT-HPNE) used in some of the experiments described in this article. We gratefully acknowledge Gabriela M. Almeida and Filipe Santos-Silva for the collaboration with in vitro cytotoxic studies at the i3S Research Unit.

Conflicts of Interest: The authors have no other relevant affiliations or financial involvement with any organization or entity with financial interest in or financial conflict manuscript apart from those disclosed.

\section{References}

1. Ellard, S.; Rothenberg, M.; Cohen, R.; Taylor, M.; Hartt, N.; Berlin, J.; Murphy, P.; Kollmannsberger, C.; Maloney, L.; Ptaszynski, M.; et al. Abstract \#3603: ARRY-334543 in ErbB2 positive metastatic breast cancer and other ErbB expressing-cancers: Experience from expansion cohorts on a phase I study. Cancer Res. 2009, $69,3603$.

2. Wang, D.S.; Patel, A.; Sim, H.M.; Zhang, Y.K.; Wang, Y.J.; Kathawala, R.J.; Zhang, H.; Talele, T.T.; Ambudkar, S.V.; $\mathrm{Xu}, \mathrm{R} . \mathrm{H} . ;$ et al. ARRY-334543 reverses multidrug resistance by antagonizing the activity of ATP-binding cassette subfamily G member 2. J. Cell. Biochem. 2014, 115, 1381-1391. [CrossRef] [PubMed]

3. Miknis, G.; Wallace, E.; Lyssikatos, J.; Lee, P.; Zhao, Q.; Hans, J.; Topalov, G.; Buckmelter, A.; Tarlton, G.; Ren, L.; et al. ARRY-334543, A potent, orally active small molecule inhibitor of EGFR and ErbB-2. Cancer Res. 2005, 65, 801 .

4. Lee, P.; Anderson, D.; Avrutskaya, A.; White, A.; Pheneger, T.; Winkler, J. In vivo activity of ARRY-543, a potent, small molecule inhibitor of EGFR/ErbB-2 in combination with trastuzumab or docetaxel. Cancer Res. 2009, 69, 2150. [CrossRef]

5. Fedele, C.; Tothill, R.W.; McArthur, G.A. Navigating the challenge of tumor heterogeneity in cancer therapy. Cancer Discov. 2014, 4, 146-148. [CrossRef] [PubMed]

6. Coelho, J.F.; Ferreira, P.C.; Alves, P.; Cordeiro, R.; Fonseca, A.C.; Góis, J.R.; Gil, M.H. Drug delivery systems: Advanced technologies potentially applicable in personalized treatments. EPMA J. 2010, 1, 164-209. [CrossRef] [PubMed]

7. Coelho, S.C.; Pereira, M.C.; Juzeniene, A.; Juzenas, P.; Coelho, M.A. Supramolecular nanoscale assemblies for cancer diagnosis and therapy. J. Controll. Release 2015, 213, 152-167. [CrossRef] [PubMed] 
8. Blanco, E.; Shen, H.; Ferrari, M. Principles of nanoparticle design for overcoming biological barriers to drug delivery. Nat. Biotechnol. 2015, 33, 941-951. [CrossRef] [PubMed]

9. Chidambaram, M.; Manavalan, R.; Kathiresan, K. Nanotherapeutics to overcome conventional cancer chemotherapy limitations. J. Pharm. Pharm. Sci. 2011, 14, 67-77. [CrossRef] [PubMed]

10. Zhang, X. Gold Nanoparticles: Recent Advances in the Biomedical Applications. Cell Biochem. Biophys. 2015, 72, 771-775. [CrossRef] [PubMed]

11. Ghosh, P.; Han, G.; De, M.; Kim, C.K.; Rotello, V.M. Gold nanoparticles in delivery applications. Adv. Drug Deliv. Rev. 2008, 60, 1307-1315. [CrossRef] [PubMed]

12. Bhattacharya, R.; Patra, C.R.; Earl, A.; Wang, S.; Katarya, A.; Lu, L.; Kizhakkedathu, J.N.; Yaszemski, M.J.; Greipp, P.R.; Mukhopadhyay, D.; et al. Attaching folic acid on gold nanoparticles using noncovalent interaction via different polyethylene glycol backbones and targeting of cancer cells. Nanomed. Nanotechnol. Biol. Med. 2007, 3, 224-238. [CrossRef]

13. Aryal, S.; Grailer, J.J.; Pilla, S.; Steeber, D.A.; Gong, S. Doxorubicin conjugated gold nanoparticles as water-soluble and $\mathrm{pH}$-responsive anticancer drug nanocarriers. J. Mater. Chem. 2009, 19, 7879-7884. [CrossRef]

14. Murugan, M.; Anthony, K.J.P.; Jeyaraj, M.; Rathinam, N.K.; Gurunathan, S. Biofabrication of gold nanoparticles and its biocompatibility in human breast adenocarcinoma cells (MCF-7). J. Ind. Eng. Chem. 2014, 20, 1713-1719. [CrossRef]

15. Coelho, S.C.; Rocha, S.; Pereira, M.C.; Juzenas, P.; Coelho, M.A. Enhancing proteasome-lnhibitor effect by functionalized gold nanoparticles. J. Biomed. Nanotechnol. 2014, 10, 717-723. [CrossRef] [PubMed]

16. Duncan, B.; Kim, C.; Rotello, V.M. Gold nanoparticle platforms as drug and biomacromolecule delivery systems. J. Controll. Release 2010, 148, 122-127. [CrossRef] [PubMed]

17. Turkevich, J.; Stevenson, P.C.; Hillier, J. A study of the nucleation and growth processes in the synthesis of colloidal gold. Discuss. Faraday Soc. 1951, 11, 55-75. [CrossRef]

18. Goulet, P.J.G.; Lennox, R.B. New Insights into Brust-Schiffrin Metal Nanoparticle Synthesis. J. Am. Chem. Soc. 2010, 132, 9582-9584. [CrossRef] [PubMed]

19. Jain, S.; Hirst, D.G.; O'Sullivan, J.M. Gold nanoparticles as novel agents for cancer therapy. Br. J. Radiol. 2012, 85, 101-113. [CrossRef] [PubMed]

20. Chhour, P.; Kim, J.; Benardo, B.; Tovar, A.; Mian, S.; Litt, H.I.; Ferrari, V.A.; Cormode, D.P. Effect of Gold Nanoparticle Size and Coating on Labeling Monocytes for CT Tracking. Bioconjugate Chem. 2017, 28, 260-269. [CrossRef] [PubMed]

21. Patra, C.R.; Bhattacharya, R.; Wang, E.; Katarya, A.; Lau, J.S.; Dutta, S.; Muders, M.; Wang, S.; Buhrow, S.A.; Safgren, S.L.; et al. Targeted Delivery of Gemcitabine to Pancreatic Adenocarcinoma Using Cetuximab as a Targeting Agent. Cancer Res. 2008, 68, 1970-1978. [CrossRef] [PubMed]

22. Coelho, S.C.; Almeida, G.M.; Santos-Silva, F.; Pereira, M.C.; Coelho, M.A. Enhancing the efficiency of bortezomib conjugated to pegylated gold nanoparticles: An in vitro study on human pancreatic cancer cells and adenocarcinoma human lung alveolar basal epithelial cells. Expert Opin. Drug Deliv. 2016, 13, 1075-1081. [CrossRef] [PubMed]

23. Daduang, J.; Palasap, A.; Daduang, S.; Boonsiri, P.; Suwannalert, P.; Limpaiboon, T. Gallic acid enhancement of gold nanoparticle anticancer activity in cervical cancer cells. Asian Pac. J. Cancer Prev. 2015, 16, 169-174. [CrossRef] [PubMed]

24. Bao, H.; Zhang, Q.; Xu, H.; Yan, Z. Effects of nanoparticle size on antitumor activity of 10-hydroxycamptothecinconjugated gold nanoparticles: In vitro and in vivo studies. Int. J. Nanomed. 2016, 11, 929-940.

25. Coelho, S.C.; Almeida, G.M.; Pereira, M.C.; Santos-Silva, F.; Coelho, M.A. Functionalized gold nanoparticles improve afatinib delivery into cancer cells. Expert Opin. Drug Deliv. 2016, 13, 133-141. [CrossRef] [PubMed]

26. Yoo, H.S.; Park, T.G. Folate-receptor-targeted delivery of doxorubicin nano-aggregates stabilized by doxorubicin-PEG-folate conjugate. J. Controll. Release 2004, 100, 247-256. [CrossRef] [PubMed]

27. Solaro, R.; Chiellini, F.; Battisti, A. Targeted Delivery of Protein Drugs by Nanocarriers. Materials 2010, 3 , 1928-1980. [CrossRef]

28. Hermanson, G.T. Chapter 3-Zero-Length Crosslinkers. In Bioconjugate Techniques, 2nd ed.; Academic Press: New York, NY, USA, 2008; pp. 213-233.

29. Buchler, P.; Reber, H.A.; Buchler, M.C.; Roth, M.A.; Buchler, M.W.; Friess, H.; Isacoff, W.H.; Hines, O.J. Therapy for pancreatic cancer with a recombinant humanized anti-HER2 antibody (herceptin). J. Gastrointest. Surg. 2001, 5, 139-146. [CrossRef] 
30. Komoto, M.; Nakata, B.; Nishii, T.; Kawajiri, H.; Shinto, O.; Amano, R.; Yamada, N.; Yashiro, M.; Hirakawa, K. In vitro and in vivo evidence that a combination of lapatinib plus $\mathrm{S}-1$ is a promising treatment for pancreatic cancer. Cancer Sci. 2010, 101, 468-473. [CrossRef] [PubMed]

31. Han, H.; Grippo, P. Drug Discovery in Pancreatic Cancer: Models and Techniques; Springer: New York, NY, USA, 2010.

32. Kimling, J.; Maier, M.; Okenve, B.; Kotaidis, V.; Ballot, H.; Plech, A. Turkevich Method for Gold Nanoparticle Synthesis Revisited. J. Phys. Chem. B 2006, 110, 15700-15707. [CrossRef] [PubMed]

33. Coelho, S.C.; Rocha, S.; Juzenas, P.; Sampaio, P.; Almeida, G.M.; Silva, F.S.; Pereira, M.C.; Coelho, M.A.N. Gold nanoparticle delivery-enhanced proteasome inhibitor effect in adenocarcinoma cells. Expert Opin. Drug Deliv. 2013, 10, 1345-1352. [CrossRef] [PubMed]

34. Baptista, P.; Doria, G.; Henriques, D.; Pereira, E.; Franco, R. Colorimetric detection of eukaryotic gene expression with DNA-derivatized gold nanoparticles. J. Biotechnol. 2005, 119, 111-117. [CrossRef] [PubMed]

35. Borzenkov, M.; Chirico, G.; D’Alfonso, L.; Sironi, L.; Collini, M.; Cabrini, E.; Dacarro, G.; Milanese, C.; Pallavicini, P.; Taglietti, A.; et al. Thermal and Chemical Stability of Thiol Bonding on Gold Nanostars. Langmuir 2015, 31, 8081-8091. [CrossRef] [PubMed]

36. Webb, B.A.; Chimenti, M.; Jacobson, M.P.; Barber, D.L. Dysregulated pH: A perfect storm for cancer progression. Nat. Rev. Cancer 2011, 11, 671-677. [CrossRef] [PubMed]

37. Lee, E.S.; Gao, Z.; Bae, Y.H. Recent progress in tumor pH targeting nanotechnology. J. Controll. Release 2008, 132, 164-170. [CrossRef] [PubMed]

38. Du, J.; Lane, L.A.; Nie, S. Stimuli-responsive nanoparticles for targeting the tumor microenvironment. J. Controll. Release 2015, 219, 205-214. [CrossRef] [PubMed]

39. Ding, H.-M.; Ma, Y.-Q. Controlling Cellular Uptake of Nanoparticles with pH-Sensitive Polymers. Sci. Rep. 2013, 3, 2804. [CrossRef] [PubMed]

(C) 2018 by the authors. Licensee MDPI, Basel, Switzerland. This article is an open access article distributed under the terms and conditions of the Creative Commons Attribution (CC BY) license (http:// creativecommons.org/licenses/by/4.0/). 